\title{
Estudio comparativo de poblaciones microbianas totales y solubilizadoras de fosfato en suelos de páramo cultivados con papa (Solanum tuberosum) en Ventaquemada-Boyacá
}

Comparative study of total microbial populations and solubilizers of phosphate in soils of paramo cultivated with potato (solanum tuberosum) in Ventaquemada - Boyacá

MAYRA ELEONORA BELTRÁN-PINEDA

Bióloga

MSc. en Ciencias Microbiología

Grupo de Investigación Gestión Ambiental

Universidad de Boyacá, Colombia mebeltran@uniboyaca.edu.co 


\title{
RESUMEN
}

Se realizó un diagnóstico microbiológico exploratorio para conocer las poblaciones de microorganismos totales y de microorganismos solubilizadores de fosfato (MSF) presentes en la rizósfera de cultivos de papa (Solanum tuberosum) en suelo de páramo, cuyas densidades pueden dar un indicio acerca de las condiciones microbiológicas del suelo, reflejando la fertilidad del mismo. El análisis de las densidades encontradas totales permite evidenciar que los suelos de la zona han visto afectada su calidad desde el punto de vista microbiológico. Se pudo demostrar la presencia de MSF en todos los suelos estudiados, este hallazgo permitirá la búsqueda de microorganismos nativos que serían la base para la futura formulación de biofertilizantes, cuya utilización en la zona constituye una estrategia de fertilización sostenible, lo cual es necesario en este tipo de áreas protegidas que han sido sobreexplotadas con fines agrícolas.

Palabras clave: Microbiología de suelos de páramo, bacterias heterótrofas totales, hongos filamentosos, microorganismos solubilizadores de fosfato.

\begin{abstract}
This paper presents the results of an exploratory diagnostic to evaluate the populations of total and Phosphate Solubilizers Microorganisms (PSM) present in the rizosphere of potato crops (Solanum tuberosum) located in a paramo region. The soil density of these plots can give an indication about the microbiological conditions and the fertility of the soil. The density analysis can be used to find conclusions about the soil quality changes from a microbiological point of view. It was possible to demonstrate the presence of PSM microorganisms in all the soil samples. This finding can be used to start a new research lead to find native microorganisms that could be the base for the formulation biofertilizers in sustainable fertilization. This type of programs is compulsory in protected areas that have been over exploited by agricultural activities.
\end{abstract}

Keywords: Paramo soils microbiology, total heterotrophic bacteria, filamentous fungi, phosphate solubilizing microorganisms. 


\section{INTRODUCCIÓN}

En Colombia los páramos ubicados en la alta montaña tropical juegan un papel importante como generadores, reguladores y almacenadores del recurso hídrico, albergan gran número de especies animales, vegetales, así como la microbiota asociada al suelo, base del sustento para el establecimiento y desarrollo de las comunidades vegetales allí encontradas (Moratto, Martínez, Valencia y Sánchez, 2005). Sin embargo, en la actualidad los páramos colombianos se están reduciendo, fragmentando y/o degradando, principalmente por deforestación con introducción de especies exóticas, minería, establecimiento de cultivos ilícitos y actividades agropecuarias (Nieto y García, 2010).

En el altiplano Cundiboyacense existen algunas zonas estratégicas definidas así por los bienes y servicios ambientales que prestan, las cuales fueron declaradas como áreas protegidas con el fin de conservarlas y restaurarlas, dentro de estas zonas se encuentra el páramo del Rabanal, cuyos suelos han sido sobreexplotados por las actividades agrícolas como el cultivo de la papa, lo cual ha generado un alto grado de degradación de este ecosistema.

El cultivo de la papa en ecosistemas de páramo se da por diferentes causas sociales y económicas, se destaca la ampliación de la frontera agrícola a manera de colonización, el aumento de la demanda de este alimento debido al crecimiento poblacional, la menor incidencia de plagas y enfermedades en zonas altas, la falta de tierras y su alto costo en zonas bajas e intermedias, además de la baja conciencia ambiental de los agricultores (Ministerio de Ambiente y FEDEPAPA, 2004). Las graves consecuencias ambientales que ha traído la destrucción del páramo, por efecto del cultivo de papa y sus actividades asociadas, permiten concluir que el uso antrópico del páramo ha llegado a límites alarmantes (Rangel, 2000). Lo anterior plantea un enorme desafío en términos de manejo ambiental, adopción de buenas prácticas y tecnologías apropiadas.

Es relevante tener presente que las comunidades microbianas asociadas a los suelos pueden actuar como indicadores de la calidad de los mismos, los microorganismos son indicadores muy sensibles y un incremento en la densidad poblacional está relacionado con la recuperación de zonas degradadas y el restablecimiento de los ciclos biogeoquímicos (Nieto y García, 2010). La fertilidad del suelo está controlada en gran medida por las actividades biogeoquímicas de la microbiota que actúa como abastecedor potencial de nutrientes para las plantas (Sivila de Cary y Angulo, 2006) y por tanto son los encargados de regenerar la fertilidad del suelo. 
Según Lizarazo (2005), el papel de los microorganismos en la nutrición y disponibilidad de nutrientes en el suelo ha sido ampliamente estudiada, especialmente orientada a aquellos microorganismos que hacen simbiosis con plantas, pero poco se ha analizado la interacción de otros grupos funcionales de microorganismos que al igual juegan un papel importante en la transformación y dinámica de los nutrientes en el suelo.

Dentro de estos grupos funcionales se destacan las comunidades microbianas implicadas en el ciclaje del fósforo, que después del nitrógeno es el elemento más limitante en la productividad vegetal (Rubio, 2002). Los microorganismos que tienen la habilidad de solubilizar fosfato insoluble juegan un rol esencial en el mantenimiento de la calidad y salud del suelo (Naik, Raman, Narayanan y Natarajan, 2008), estos son ubicuos y su número varía de un suelo a otro (Kucey, Jansen y Leggett, 1983), además son relevantes en ecosistemas que por su origen, características químicas o degradación, presentan baja fertilidad, principalmente de fósforo y nitrógeno disponible (Nieto y García, 2010) como los ecosistemas de páramo.

El fósforo es uno de los nutrientes limitantes para el crecimiento vegetal debido a su baja biodisponiblidad en los suelos (Feng, Lu, Sheng, Wang y Mao, 2004), esta condición implica la necesidad de aplicar insumos químicos como los fertilizantes fosforados para suplir los requerimientos de las plantas, sin embargo, se conoce que estos tienden a fijarse una vez son aplicados, lo que resulta en la baja utilización por parte de los cultivos y la alta acumulación en los suelos (Alam y Ladha, 2004). Por lo tanto, la actividad de los microorganismos que son capaces de solubilizar y mineralizar este nutriente es vital en todos los agroecosistemas (Guang-Can, Shu-Tun, Miao-Ying y Guang-Hui, 2008).

La papa (Solanum tuberosum) es el cultivo que ocupa un lugar preferente en estas zonas ya que cada año son sembradas de 3500 a 5000 hectáreas (Vélez, 2009), debido a que las condiciones fisicoquímicas de estos suelos lo favorecen. A pesar del rol de este cultivo en el escenario económico mundial y nacional, estudios acerca de la presencia de comunidades microbianas en estos ecosistemas son escasos (Brito, Dusi, Xavier y Rumjanek, 2008). El objetivo de esta investigación en primera medida es contribuir al conocimiento de los microorganismos de suelos de páramo boyacenses cultivados con papa (Solanum tuberosum), por medio de una aproximación a las densidades de las poblaciones microbianas (bacterias heterótrofas y hongos filamentosos) que pueden considerarse indicadores de la calidad de los suelos, así como conocer la existencia y densidad de los microorganismos solubilizadores de fosfato que son poco estudiados en este tipo de suelo y cuya existencia podría favorecer a la disminución de la aplicación de fertilizantes a estos suelos con vocación agrícola intensiva. 


\section{METODOLOGÍA}

\section{Zona de estudio}

El muestreo de suelos se realizó en la vereda San José del Gacal del municipio de Ventaquemada - Boyacá que está localizada en inmediaciones del páramo del Rabanal a una altura de $3200 \mathrm{msnm}$, estos suelos se caracterizan por presentar una alta susceptibilidad al deterioro, bajos niveles de fertilidad, fuerte acidez, temperatura edáfica baja, pedregosidad y alta retención de humedad (CORPOBOYACA, CORPOCHIVOR, 2005). Se tomaron muestras representativas de cuatro fincas cultivadas con papa (Solanum tuberosum). De cada finca se tomaron diez muestras de suelo rizosférico que fueron homogenizadas y divididas en tres submuestras compuestas, las muestras se tomaron en puntos diferentes de los terrenos realizando un desplazamiento en zig-zag, donde cada punto estuvo separado cinco metros. Las muestras fueron almacenadas en refrigeración y transportadas al laboratorio de Microbiología de la Universidad de Boyacá para su posterior análisis.

\section{Análisis físico químico del suelo}

Los parámetros fisicoquímicos de los suelos se determinaron de acuerdo a técnicas estandarizadas (Horwitz, 2000). Se utilizó para textura el método de Bouyucos, (Bouyucos, 1962), para pH la relación 1:1 suelo:agua, porcentaje de materia orgánica según Walkey-Black, (Walkley \& Black,1934), fósforo disponible por el método de Bray II y colorimetría (Bray \& Kurtz, 1945), $\mathrm{Al}^{+3}$ según valoración ácido-base $(\mathrm{KCl}), \mathrm{Ca}, \mathrm{Mg}$, Na y K por extracción con $\mathrm{NH}_{4 \mathrm{Ac}}$ y absorción atómica.

\section{Recuentos totales de microorganismos}

Con el fin de tener una estimación de la población global de microorganismos cultivables dentro de las fincas analizadas, se realizó el recuento de microorganismos totales discriminando entre bacterias y hongos según la metodología propuesta por Vanegas, Landazábal, Melgarejo, Beltrán y Uribe (2013). Este se realizó mediante series de dilución y siembra en placa, determinando el Log de UFC/g de suelo. Para el recuento de bacterias heterótrofas totales se utilizó el medio de cultivo agar nutritivo (peptona de carne $5 \mathrm{~g} / \mathrm{L}$; extracto de carne $3 \mathrm{~g} / \mathrm{L}$; y agar $12 \mathrm{~g} / \mathrm{L}$ con un pH final 7.0+/- 0.2) con incubación por 24-48 horas a $28^{\circ} \mathrm{C}$. Por otra parte, los recuentos de los hongos filamentosos se realizaron usando el medio de cultivo PDA (infusión de papa $4 \mathrm{~g} / \mathrm{L}$, glucosa, $20 \mathrm{~g} / \mathrm{L}$ y agar $15 \mathrm{~g} / \mathrm{L}$, pH final 6.0+/-0.2) con incubación por 7 días a $28^{\circ} \mathrm{C}$.

\section{Recuentos de microorganismos solubilizadores de fosfato}

Se realizaron recuentos de microorganismos solubilizadores de fosfato para todas las muestras de suelo obtenidas utilizando el método de diluciones seriadas y siembra en medio selectivo. Se utilizó 
el medio de cultivo NBRIP (Nacional Botanical Research Institute Phosphate growth medium) (Nautiyal, 1999). Este medio contiene (glucosa $10 \mathrm{~g} / \mathrm{L},\left(\mathrm{NH}_{4}\right)_{2} \mathrm{SO}_{4} 0,1 \mathrm{~g} / \mathrm{L}, \mathrm{KCl} \mathrm{0,2} \mathrm{g} / \mathrm{L}, \mathrm{MgSO}_{4} \cdot 7 \mathrm{H}_{2} \mathrm{O} 0,25 \mathrm{~g} / \mathrm{L}$, $\mathrm{MgCl}_{2} \cdot 6 \mathrm{H}_{2} \mathrm{O} 5 \mathrm{~g} / \mathrm{L}$, agar $14 \mathrm{~g} / \mathrm{L}$ con un $\mathrm{pH}$ final de 7,0 y enriquecido con fosfato tricálcico $\mathrm{Ca}_{3} \mathrm{PO}_{4}$ al $0.5 \%$ como fuente de fosfato inorgánico e insoluble.

Las cajas se incubaron a $28^{\circ} \mathrm{C}$ durante 14 días manteniendo estas condiciones tanto para bacterias como para hongos. Al final de periodo de incubación se realizó el recuento de microorganismos solubilizadores de fosfato tricálcico que pueden seleccionarse por la aparición de halos claros alrededor de las UFC según Nautiyal (1999)

\section{Análisis de resultados}

El análisis estadístico se realizó con ayuda de los programas MINITAB ${ }^{\circledR}$ Release 14. Statistical Software y Statgraphics plus versión 5.1. Para determinar la variación de las poblaciones microbianas en cada uno de los terrenos estudiados se realizaron pruebas de análisis de varianza (ANOVA) después de comprobar los supuestos estadísticos de normalidad de datos mediante la prueba Kolmogorov-Smirnov y homogeneidad de varianza mediante la prueba de Bartlett. Adicionalmente se realizaron pruebas de correlación de Pearson para establecer posibles relaciones entre los recuentos encontrados y las características fisicoquímicas de los suelos en estudio. Los gráficos se realizaron mediante el software SIGMAPLOT versión 10.0 .

\section{RESULTADOS Y DISCUSIÓN}

\section{Análisis físico químico del suelo}

En general según el análisis fisicoquímico de los suelos se puede afirmar que estos presentan texturas que van desde franco arcilloso arenoso a suelos orgánicos a diferencia de los reportado por Flórez y Uribe (2011), quienes analizando suelos de páramo cultivados con papa encontraron suelos con texturas que van desde arcillosos a arcillosos limosos. El pH de los suelos puede ser considerado como ácido al igual que lo encontrado en los suelos de páramo analizados por Moratto, Martínez, Valencia y Sánchez (2005) y suelos de páramo de la cordillera de los Andes estudiados por Sarmiento y Bottner (2002). Los contenidos de materia orgánica presentan valores medios y oscilan entre un $13,45 \%$ en la finca Villa Rosa a 21,2\% en la finca Zarcillejos a diferencia de los reportados por Moratto, et al. (2005) y quienes reportaron niveles altos de materia orgánica en suelos de este tipo de ecosistemas.

En cuanto al contenido de fósforo, Flórez y Uribe (2011) encontraron valores de hasta $107 \mathrm{mg} / \mathrm{kg}$ en suelo de páramo que son valores mayores a los encontrados en los suelos estudiados, en donde se evidencian contenidos medios en la finca El Recuerdo y La Escuela y contenidos deficientes en las 
fincas Villa Rosa y Zarcillejos. En los demás elementos evaluados tales como el $\mathrm{Al}, \mathrm{Ca}, \mathrm{Mg}, \mathrm{K}, \mathrm{Na}$ y $\mathrm{CIC}$ (capacidad de intercambio catiónico) no se evidencian diferencias marcadas entre los suelos en estudio (Tabla 1).

\begin{tabular}{|c|c|c|c|c|c|c|c|c|c|c|}
\hline \multirow{2}{*}{ FINCA } & \multirow{2}{*}{ TEXTURA } & \multirow{2}{*}{$\mathrm{pH}$} & \multirow{2}{*}{$\% \mathrm{MO}$} & \multirow{2}{*}{$\begin{array}{l}\mathrm{P}(\mathrm{ppm}) \\
\text { Bray II }\end{array}$} & \multicolumn{6}{|c|}{ meq/100g } \\
\hline & & & & & $\mathrm{Al}$ & $\mathrm{Ca}$ & $\mathrm{Mg}$ & K & $\mathrm{Na}$ & CIC \\
\hline El Recuerdo & $\begin{array}{c}\text { Franco arcilloso } \\
\text { arenoso }\end{array}$ & 5,07 & 19,67 & 57,03 & 2,58 & 2,45 & 0,20 & 0,37 & 0,08 & 5,68 \\
\hline Villa Rosa & Franco arenoso & 4,72 & 13,45 & 37,76 & 2,22 & 2,09 & 0,37 & 0,22 & 0,13 & 5,04 \\
\hline Zarcillejos & Orgánico & 5,2 & 21,2 & 18,8 & 1,0 & 3,48 & 0,44 & 1,12 & 0,05 & 6,69 \\
\hline La Escuela & Franco arenoso & 5,2 & 15,7 & 60,5 & 1,0 & 2,04 & 0,16 & 0,11 & 0,07 & 3,38 \\
\hline
\end{tabular}

Tabla 1. Características fisicoquímicas de los suelos estudiados

\section{Recuentos microbianos totales}

En general, los recuentos de microorganismos totales en los suelos en estudio son bajos si se comparan con los reportados en otros estudios en suelos de páramo como los realizados por Bernal, et al. (2006) quien realizó el recuento total de microorganismos en el páramo de Guerrero en Zipaquirá encontrando valores de 7,34 Log UFC/g de suelo, valor superior al registrado en este estudio. Igualmente Sivila de Cary y Angulo (2006) realizaron como parte de su estudio recuentos de bacterias y hongos en suelos del altiplano Boliviano encontrando recuentos de $7.06 \mathrm{Log} \mathrm{UFC} / \mathrm{g}$ para las poblaciones bacterianas y recuentos de hongos de 5,9 Log UFC/g que son valores superiores a los obtenidos en este estudio tanto para hongos como para bacterias.

Igualmente en investigaciones realizadas en suelos agrícolas cultivados con papa muestran recuentos mayores a los obtenidos en esta investigación como en la aproximación realizada por Calvo, Meneses y Zúñiga (2008), en donde se registra siempre una mayor población de bacterias que estuvieron en el orden de $10^{6}$ y $10^{8}$ con relación al recuento de hongos que estuvieron en el orden de $10^{4}$ y $10^{5}$. Numerosos estudios han mostrado que el manejo agrícola disminuye la biodiversidad del suelo y altera 
la estructura de las comunidades biológicas del mismo si se compara con un bosque nativo o un ecosistema de pradera (Crossley, Mueller y Perdue, 1992), lo que podría indicar que los suelos en estudio tendrían afectada su calidad desde el punto de vista microbiológico debido a las bajas densidades reportadas y conociendo el rol de la microbiota en la regulación de la fertilidad de los suelos se podría inferir que dicha característica se está viendo afectada en la zona.

En esta investigación los recuentos bacterianos oscilaron entre 2,62 y 3,69 Log de UFC/g de suelo para las fincas El Recuerdo y La Escuela respectivamente (Figura 1). No se encontró una diferencia estadísticamente significativa entre los recuentos de bacterias heterótrofas totales para las fincas en estudio (gl:23 y p:0,259), las concentraciones medias de materia orgánica encontradas en todos los suelos según el análisis fisicoquímico podrían explicar en alguna medida este comportamiento, se conoce que la materia orgánica en los suelos es heterogénea porque puede tener múltiples orígenes y diferentes estados de descomposición (Osorio, 2010), lo que brinda distintos tipos de sustratos para las poblaciones bacterianas eso podría determinar la presencia equitativa y constante de estos microorganismos en los suelos analizados.

Según el análisis fisicoquímico de las fincas se reporta un pH ácido en la totalidad de los terrenos y uno de los factores más importantes que determinan la presencia de los microorganismos en el suelo es el $\mathrm{pH}$, una modificación de éste puede activar o casi inactivar las enzimas de los microorganismos; el pH también actúa sobre la disponibilidad o fijación de minerales nutritivos lo que puede afectar las densidades de microorganismos asociados a los suelos (Calvo et al., 2008) lo que podría favorecer densidades de bacterias heterótrofas similares en los suelos estudiados. 


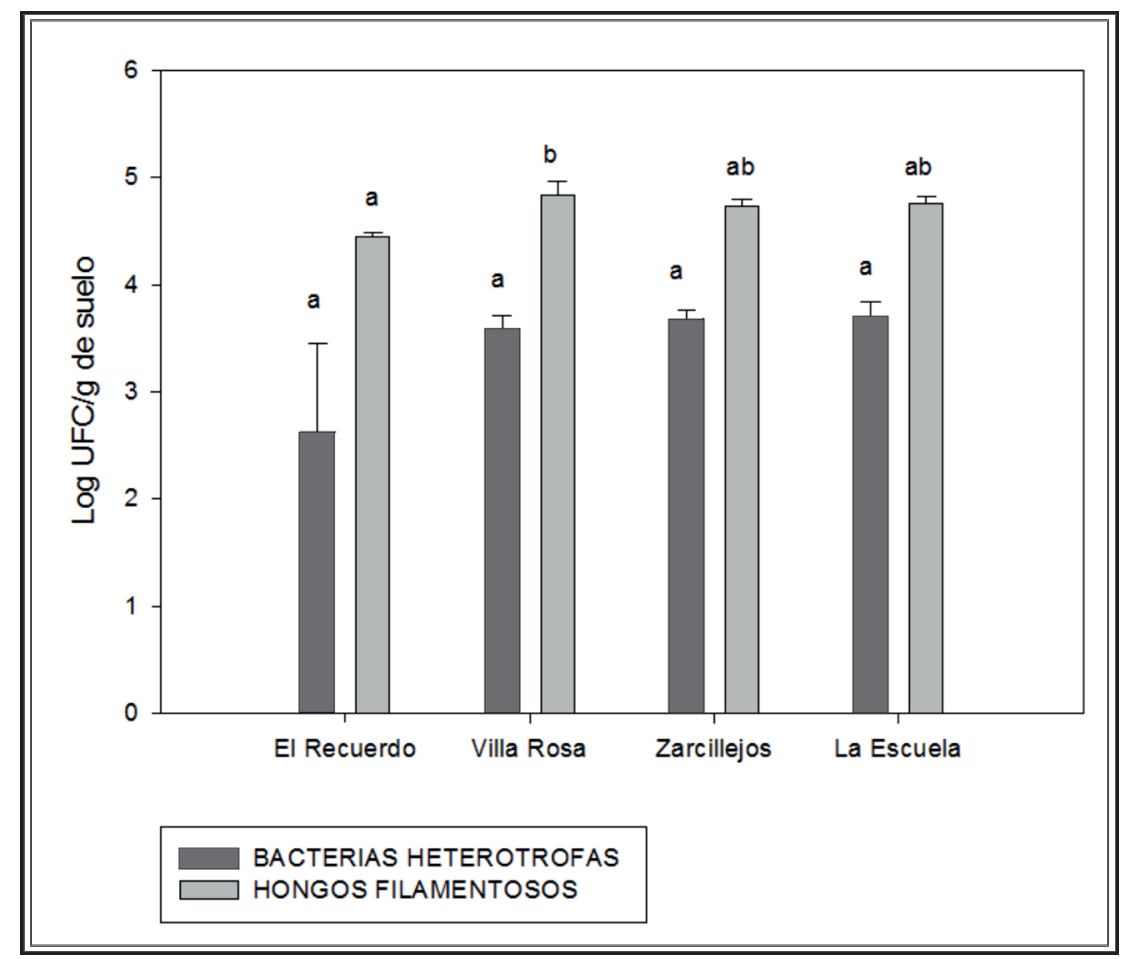

Figura 1. Recuentos bacterianos y de hongos filamentosos para las cuatro fincas cultivadas con papa (Solanum tuberosum) en la vereda San José del Gacal del municipio de Ventaquemada-Boyacá. Las barras corresponden a la media con su respectivo error estándar. Para el recuento de hongos filamentosos las letras iguales no difieren significativamente según la prueba de Tukey al 5\%.

Por otra parte los recuentos de los hongos filamentosos oscilaron entre 4,45 Log UFC/g de suelo para la finca El Recuerdo y 4,83 Log UFC/g de suelo para la Villa Rosa (Figura 1), a diferencia de lo que ocurrió con los recuentos de bacterias heterótrofas, en estos recuentos si se evidenciaron diferencias significativas entre las fincas en estudio (gl:23 y p:0,014). Se han reportado múltiples causas que explican la variabilidad de las poblaciones de microorganismos en suelos. Estudios como los realizados por Taylor, Wilson, Mills y Burns (2002) sugieren que los recuentos microbianos pueden verse influenciados por el contenido de agua y materia orgánica, elevadas concentraciones de aluminio y en general disponibilidad de nutrientes. Según Killian, et al. (2001), la cantidad de microorganismos que se pueden encontrar en el suelo depende de otros factores como la temporada, el tipo de suelo, la vegetación, el contenido de humedad, el tipo de labranza y fertilización. Adicionalmente se conoce que las poblaciones microbianas en los suelos son reguladas por la temperatura, la concentración de protones y suministro de oxígeno (Scholer, Dilly y Munch, 2003). 
En este estudio se pudo observar que los recuentos de las poblaciones fúngicas son mayores que los de las poblaciones de bacterias heterótrofas totales, esto ha sido reportado en otros estudios en suelos agrícolas como los realizados por Bardgett y McAllister (1999) quienes afirman que en suelos ácidos donde los nutrientes son limitantes, es conocido que la biomasa fúngica es mayor que las bacterias; de hecho la finca que exhibió las mayores cantidades de hongos filamentosos fue Villa Rosa que presenta el pH más ácido. Según Calvo, et al. (2008), los hongos, dado su mayor tamaño, constituyen la biomasa más significativa representando un 10 a $20 \%$ de la microbiota total, esto es aproximadamente $10^{5}$ a $10^{6}$ organismos/gramo de suelo, aunque según Osorio (2010), los hongos pueden representar alrededor del 70\% de la biomasa en los suelos.

Sin embargo, en aproximaciones como las realizadas por Grayston, Griffith, Mawdsley, Campbell y Bardgett (2001) se confirmó que el principal contribuyente de biomasa microbiana en tierras con manejo agrícola son las bacterias. Se ha sugerido que el número de organismos en la rizósfera depende del suministro de sustrato a partir de la raíz y la utilización eficiente de esos sustratos por parte de los microorganismos determina su densidad de población en la misma (Bowen, 1979).

\section{Recuento de microorganismos solubilizadores de fosfato}

A pesar del rol del cultivo de papa en el escenario económico mundial y nacional, estudios acerca de las interacciones con las comunidades microbianas asociadas a los ciclos de nutrientes son escasos. En este estudio se pudo corroborar la presencia de poblaciones microbianas solubilizadoras de fosfato en todos los suelos estudiados, lo que posiblemente indica que estarían desempeñando un papel importante en la nutrición de las plantas de papa asociadas a los suelos, al proveer el fósforo limitante en el sistema (Nieto, et al., 2010). Cabe mencionar que la mayor presencia de microorganismos solubilizadores de fosfato en los suelos puede ser favorable para el desarrollo de las plantas pues garantizaría una mayor disponibilidad de fosfatos asimilables, así mismo, la disponibilidad de fósforo en los suelos está determinada por la actividad de las bacterias solubilizadoras y su grado de eficiencia (Torres y Lizarazo, 2006).

Si se realiza una comparación entre los recuentos de microorganismos solubilizadores de la zona de estudio y los recuentos totales que dan una estimación de la carga microbiana total de los suelos, podemos evidenciar que el porcentaje de bacterias solubilizadoras es alto si se compara con el recuento obtenido para las bacterias heterótrofas totales, pero por parte de los hongos la situación es diferente, porque solo un pequeño porcentaje de las comunidades de hongos filamentosos presentes en los suelos en estudio poseen esta capacidad. Algunos autores indican que solo un pequeño porcentaje de los aislados del rizoplano y de la rizósfera, poseen la habilidad de solubilizar fosfatos (Katznelson, Peterson y Roualt, 1962). Se estima que de la población total de un suelo dado, el $50 \%$ pueden ser bacterias solubilizadoras mientras que solo el $0,1-0,5 \%$ corresponde a los hongos solubilizadores (Gyaneshwar, Naresh, Kumar, Parekh y Poole, 2000), lo cual podría explicar los bajos niveles de hongos solubilizadores en la zona de estudio. 
En esta investigación se encontraron resultados contrastantes para los recuentos de los microorganismos solubilizadores de fosfato en las fincas en estudio. Los recuentos de hongos filamentosos con capacidad solubilizadora de fosfato oscilaron entre $0,5 \mathrm{Log}$ UFC/g de suelo para las finca Villa Rosa y La Escuela y 1,50 Log UFC/g de suelo para la finca El Recuerdo (Figura 2). No se evidenciaron diferencias significativas entre las fincas en estudio para este tipo de microorganismos (gl:23 y p:0,597).

Los recuentos de bacterias solubilizadoras de fosfato oscilaron entre 1,50 Log UFC/g de suelo para la finca La Escuela y el máximo recuento se encontró en la finca El Recuerdo con recuentos de 3,94 Log UFC/g de suelo. Se evidencian diferencias significativas entre fincas (gl:23 y p:0,018). Kucey, Janzen y Leggett (1989) señalaron que esta variación se debe al clima y a la historia del cultivo en los suelos, por otra parte Kobus (1962) estableció que la diferencia en el número de microorganismos solubilizadores de fosfato está determinada por el tipo de suelo y plantas asociadas a éste, más que por las características físicas y químicas del mismo.

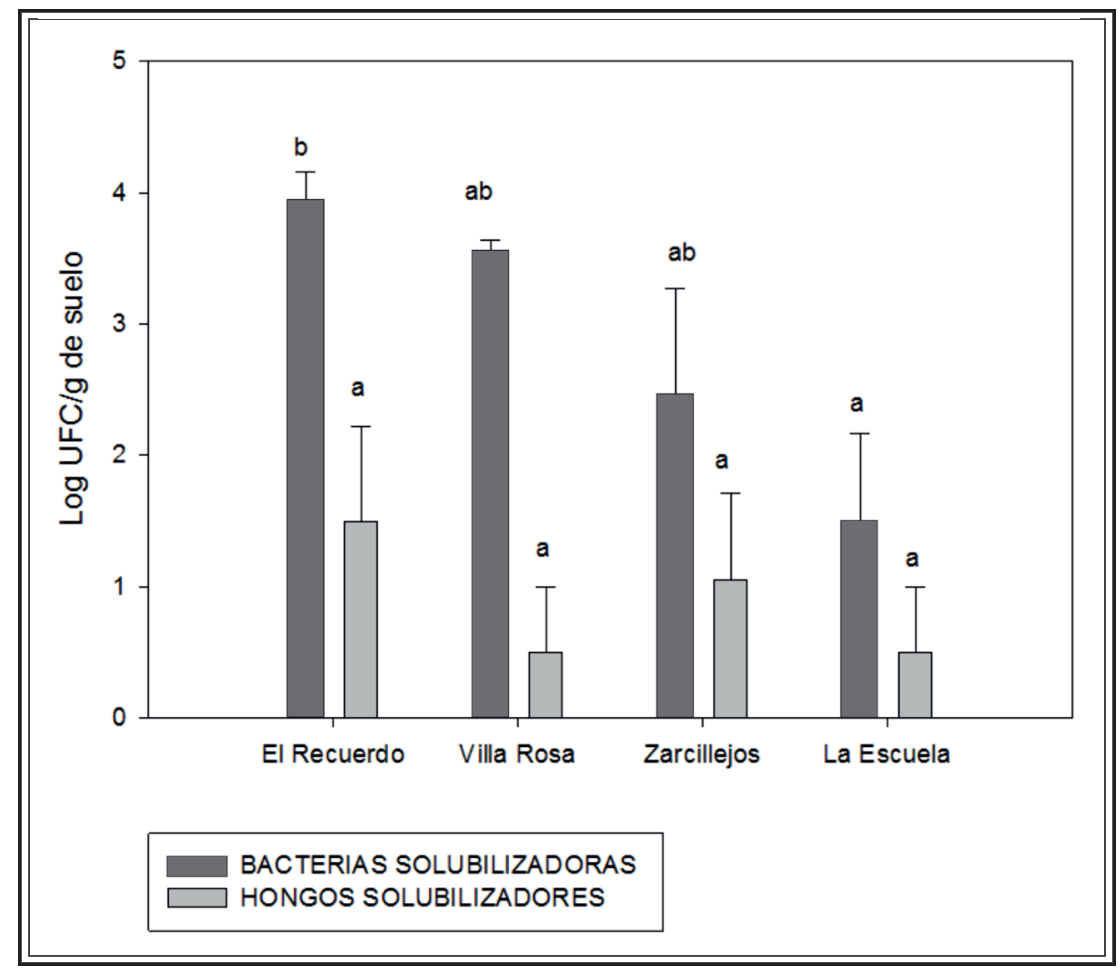

Figura 2. Recuentos de bacterias y hongos solubilizadores de fosfato para las cuatro fincas cultivadas con papa (Solanum tuberosum) en la vereda San José del Gacal del municipio de Ventaquemada-Boyacá. Las barras corresponden a la media con su respectivo error estándar. Para el recuento de bacterias solubilizadoras de fosfato las letras iguales no difieren significativamente según la prueba de Tukey al 5\% 
Las variedades de papa pueden jugar un rol importante sobre las poblaciones microbianas de la rizósfera confirmando una vez más que los exudados influyen mucho en la dinámica de dichas poblaciones. El efecto de la variedad o de la forma de cultivo de la planta sobre las comunidades microbianas asociadas ya ha sido reportado por Grayer, et al. (2004). Esto se debe a que a pesar de ser especies vegetales del mismo género, pueden presentar diferencias fisiológicas que se traducen en la composición bioquímica de los exudados radiculares (Silva, Salles, Seldini y Elsas, 2003), lo que origina una microflora especie-específica la cual puede permanecer durante las etapas de desarrollo de las plantas (Wieland, Newmann y Backhaus, 2001; Calvo, et al., 2008).

Se puede evidenciar que en este estudio los recuentos de las poblaciones de bacterias solubilizadoras de fosfato son mayores a los recuentos de hongos solubilizadores de fosfato. Resultados similares fueron encontrados por Beltrán (2009), quien trabajando en suelos agrícolas encontró que las poblaciones bacterianas predominan sobre las de hongos filamentosos con capacidad solubilizadora. Se sabe que existe una población considerable de bacterias solubilizadoras en suelos y rizósfera del plantas (Rodríguez y Fraga, 1999) y que las bacterias son los microorganismos que predominantemente solubilizan fosfatos minerales en los suelos comparados con los hongos y los actinomicetos (Guang-Can, et al., 2008). Además es conocido que la abundancia de bacterias en la rizósfera en comparación con otros microorganismos se puede deber a su rápido crecimiento y la habilidad que presentan de utilizar un amplio rango de sustratos como fuentes de carbono o nitrógeno (Glick, 1995).

Con respecto a otros estudios, Torres y Lizarazo (2006) evaluaron este tipo de microorganismos en cultivos de papa encontrado poblaciones solubilizadoras de hasta 1,31 Log UFC/g de suelo, valores inferiores a los reportados en nuestros suelos. Fernández, Zalba y Gómez (2005), estudiaron bacterias solubilizadoras de fosfato en diferentes suelos agrícolas encontrando un promedio de 3,47 Log UFC/g de suelo, estos valores son comparables con los obtenidos en este estudio. Es evidente la alta densidad de bacterias solubilizadoras de fosfato en los suelos analizados con respecto a otros tipos de suelos, esto pudo verse favorecido por la alta actividad agrícola que se evidencia en la zona. Torres y Lizarazo (2006) sugieren que los suelos agrícolas pueden presentar mayor número de microorganismos solubilizadores de fosfato que en los suelos forestales y que uno de los factores que influye sobre este parámetro es el pH del suelo modificado por la adición de fertilizantes, que no solo aumenta el pH sino que también produce un aumento en la disponibilidad de nutrientes, lo que puede favorecer el crecimiento poblacional de los solubilizadoras de fosfato. Sin embargo esta situación es contradictoria para los hongos filamentosos encontrados en los suelos que muestran esta capacidad donde sus densidades poblacionales fueron bajas.

\section{Correlaciones entre recuentos microbianos y características fisicoquímicas de los suelos en estudio}

Al realizar el análisis de correlación entre los recuentos microbianos y los parámetros fisicoquímicos del suelo no se lograron establecer relaciones lineales estadísticamente significativas entre dichas 
variables $(p>0,05)$. Esto indicaría que la presencia de microorganismos en los suelos no se asocia directamente con algún parámetro fisicoquímico específico sino que son toda una serie de factores los que interactúan para determinar la presencia y abundancia de la microflora en la zona de estudio (Tabla 2).

\begin{tabular}{|c|c|c|c|c|}
\hline $\begin{array}{l}\text { CARACTERÍSTICAS } \\
\text { FÍSICOQUÍMÍCAS }\end{array}$ & $\begin{array}{c}\text { BACTERIAS } \\
\text { HETERÓTROFAS }\end{array}$ & $\begin{array}{c}\text { HONGOS } \\
\text { FILAMENTOSOS }\end{array}$ & $\begin{array}{c}\text { BACTERIAS } \\
\text { SOLUBILIZADORAS }\end{array}$ & $\begin{array}{c}\text { HONGOS } \\
\text { SOLUBILIZADORES }\end{array}$ \\
\hline $\mathrm{pH}$ & $\begin{array}{l}\text { r:- }-0,447 \\
\text { p: } 0,553\end{array}$ & $\begin{array}{l}\mathrm{r}:-0,319 \\
\mathrm{p}: 0,681\end{array}$ & $\begin{array}{l}r: 0,535 \\
\mathrm{p}: 0,465\end{array}$ & $\begin{array}{l}\mathrm{r}: 0,323 \\
\mathrm{p}: 0,677\end{array}$ \\
\hline$\% \mathrm{MO}$ & $\begin{array}{l}\text { r: }-0,347 \\
\text { p: } 0,653\end{array}$ & $\begin{array}{l}\text { r: }-0,610 \\
\text { p: } 0,390\end{array}$ & $\begin{array}{c}r:-0,626 \\
\mathrm{p}: 0,374\end{array}$ & $\begin{array}{l}\mathrm{r}: 0,812 \\
\mathrm{p}: 0,188\end{array}$ \\
\hline$P$ & $\begin{array}{l}\text { r: }-0,447 \\
\text { p: } 0,553\end{array}$ & $\begin{array}{l}\text { r: }-0,391 \\
\text { p: } 0,609\end{array}$ & $\begin{array}{l}r:-0,041 \\
\mathrm{p}: 0,959\end{array}$ & $\begin{array}{l}r:-0,003 \\
\mathrm{p}: 0,997\end{array}$ \\
\hline $\mathrm{Al}$ & $\begin{array}{l}\text { r: }-0,780 \\
\text { p: } 0,220\end{array}$ & $\begin{array}{l}\text { r: }-0,509 \\
\text { p: } 0,491\end{array}$ & $\begin{array}{l}r: 0,934 \\
p: 0,066\end{array}$ & $\begin{array}{l}r: 0,415 \\
\mathrm{p}: 0,585\end{array}$ \\
\hline $\mathrm{Ca}$ & $\begin{array}{l}\text { r: } 0,098 \\
\text { p: } 0,902\end{array}$ & $\begin{array}{l}\text { r: }-0,129 \\
\text { p: } 0,871\end{array}$ & $\begin{array}{l}\mathrm{r}:-0,047 \\
\mathrm{p}: 0,953\end{array}$ & $\begin{array}{l}r: 0,480 \\
\mathrm{p}: 0,520\end{array}$ \\
\hline $\mathrm{Mg}$ & $\begin{array}{l}\text { r: } 0,421 \\
\text { p: } 0,579\end{array}$ & $\begin{array}{l}\text { r: } 0,438 \\
\text { p: } 0,562\end{array}$ & $\begin{array}{c}\mathrm{r}:: 0,169 \\
\mathrm{p}: 0,831\end{array}$ & $\begin{array}{c}r:-0,058 \\
\mathrm{p}: 0,942\end{array}$ \\
\hline K & $\begin{array}{l}r: 0,151 \\
\text { p: } 0,849\end{array}$ & $\begin{array}{l}\mathrm{r}:-0,057 \\
\mathrm{p}: 0,943\end{array}$ & $\begin{array}{l}\mathrm{r}:-0,033 \\
\mathrm{p}: 0,967\end{array}$ & $\begin{array}{l}r: 0,424 \\
p: 0,576\end{array}$ \\
\hline $\mathrm{Na}$ & $\begin{array}{l}\text { r: }-0,044 \\
\text { p: } 0,956\end{array}$ & $\begin{array}{l}\text { r: } 0,315 \\
\text { p: } 0,685\end{array}$ & $\begin{array}{l}\mathrm{r}: 0,533 \\
\mathrm{p}: 0,467\end{array}$ & $\begin{array}{l}\mathrm{r}:-0,413 \\
\mathrm{p}: 0,587\end{array}$ \\
\hline $\mathrm{CIC}$ & $\begin{array}{l}r:-0,245 \\
\text { p: } 0,755\end{array}$ & $\begin{array}{l}\text { R: }-0,300 \\
P: 0,700\end{array}$ & $\begin{array}{l}\mathrm{r}: 0,498 \\
\mathrm{p}: 0,502\end{array}$ & $\begin{array}{l}\mathrm{r}: 0,647 \\
\mathrm{p}: 0,353\end{array}$ \\
\hline
\end{tabular}

r: Coeficiente de correlación de Pearson; $p$ : valor P.

Tabla 2. Correlaciones entre recuentos microbianos y las características fisicoquímicas de los suelos de las cuatro fincas cultivadas con papa (Solanum tuberosum) en la vereda San José del Gacal del municipio de Ventaquemada-Boyacá

A pesar de no haberse encontrado relación lineal estadísticamente significativa entre los parámetros microbiológicos y fisicoquímicos, es importante hacer un análisis acerca del efecto de las características fisicoquímicas sobre las poblaciones microbianas autóctonas, cabe indicar que en los suelos en estudio, la finca que presentó los menores recuentos totales fue El Recuerdo, esto podría explicarse debido a que la textura de ese suelo es franco arenosa arcillosa y es conocido que el contenido de arcilla podría dificultar la difusión de oxígeno entre los agregados del suelo (Sylvia, Fuhrmann, Hartel y Zuberer,1995), lo que podría limitar el crecimiento de microorganismos, teniendo en cuenta que éste es un factor ambiental limitante. Calvo, et al. (2008) mencionan que la presencia de un mayor porcentaje de materia orgánica puede favorecer el desarrollo de una mayor diversidad de microorganismos, sin embargo los contenidos de materia orgánica de las fincas Villa Rosa y La Escuela son los más bajos de las cuatro fincas evaluadas y aun así muestran los recuentos totales más altos. 
En cuanto a los microorganismos solubilizadores de fosfato, los recuentos más altos se reportaron en la finca El Recuerdo. Se conoce que la concentración de fósforo del suelo puede determinar en gran medida la presencia de los microorganismos solubilizadores. Las concentraciones de $\mathrm{P}, \mathrm{Al}$ y Ca en esta finca son las más elevadas de los suelos en estudio y esto podría indicar que el fósforo puede estar unido a estos cationes haciéndolo insoluble e inasequible para las plantas, lo que incrementaría el sustrato para la actividad de este tipo de microorganismos. Los recuentos más bajos de solubilizadores se reportaron en la fincas Villa Rosa y La Escuela que si bien tienen alto contenido de fósforo, presentan una materia orgánica baja y se conoce que la materia orgánica del suelo es un factor crítico que restringe el crecimiento de plantas y microorganismos asociados a la rizósfera de las mismas (Kim, et al., 2011)

La dinámica de las poblaciones rizosféricas es gobernada por muchos procesos interactuantes que influencian el tamaño de la población, esos procesos incluyen el crecimiento bacteriano, microflora competitiva, supervivencia o muerte, emigración e inmigración que se ven influenciados por el ambiente físico, químico y biológico de la rizósfera (Loper, Haack y Schroth, 1985). Por lo tanto es difícil establecer correlaciones estadísticamente significativas entre parámetros biológicos y fisicoquímicos para tratar de entender el comportamiento de las poblaciones microbianas en los suelos.

\section{CONCLUSIONES}

El diagnóstico microbiológico realizado permitió definir que los recuentos de microorganismos totales en la zona de estudio son bajos con relación a los reportados en otros estudios (Bernal et al., 2006; Sivila de Cary y Angulo, 2006; Calvo, Meneses y Zúñiga, 2008), lo que podría indicar que estos suelos tendrían afectada su calidad desde el punto de vista microbiológico, y conociendo el rol de la microbiota en la regulación de la fertilidad de los suelos y las bajas o deficientes concentraciones de fósforo reportadas, se podría inferir que estos no son los mejores para ser utilizados con fines agrícolas, sin embargo, a pesar de esta condición, en la zona se evidencia actividad agrícola intensiva sustentada en gran medida por la aplicación de fertilizantes, lo que conduce a la degradación paulatina del ecosistema.

Con respecto a los recuentos de microorganismos solubilizadores de fosfato, se evidenció la presencia tanto de hongos como bacterias que muestran esta actividad en los suelos, las densidades de hongos solubilizadores fueron bajas con relación a las densidades de hongos filamentosos totales mientras que se destacan las altas densidades poblacionales para las bacterias que poseen este rasgo con respecto al recuento de bacterias heterótrofas totales, lo que puede favorecer a la selección de microorganismos promisorios para la fabricación de biofertilizantes en la zona. 
Los suelos estudiados mostraron características fisicoquímicas típicas de este tipo ecosistemas, en donde se evidencian valores de pH ácidos así como lo reportado por Moratto, et al. (2005) y Sarmiento y Botter (2002), valores medios de materia orgánica y valores de bajos a deficientes de fósforo. Si bien no se evidenciaron relaciones lineales estadísticamente significativas en el análisis de correlación entre recuentos microbianos y características fisicoquímicas de los suelos, se realizaron algunos análisis que tratan de explicar de alguna manera la dinámica de dichas poblaciones microbianas en los suelos estudiados, como el efecto de la textura del suelo sobre la difusión del oxígeno, el contenido de materia orgánica y de fósforo, que son factores ambientales determinantes y limitantes para el establecimiento de poblaciones microbianas en los suelos.

La dinámica de las poblaciones rizosféricas es compleja y está gobernada por muchos procesos interactuantes que influencian el tamaño de la población, esos procesos incluyen el crecimiento bacteriano, microflora competitiva, supervivencia o muerte, emigración e inmigración en la rizósfera (Loper, Haack y Schroth, 1985). Por lo tanto es difícil establecer correlaciones estadísticamente significativas entre parámetros microbiológicos y fisicoquímicos que expliquen el comportamiento de las poblaciones microbianas en los suelos. 


\section{REFERENCIAS BILIBLIOGRÁFICAS}

Alam, M. y Ladha, J. (2004). Optimizing phosphorus fertilization in an intensive vegetable-rice cropping system. Biol. Fertil. Soils 40:277-283.

Bardgett, R. y McAlister, E. (1999). The measurement of soil fungal: bacterial biomass ratios as an indicator of ecosystem self regulation in temperate meadow grasslands. Biol Fertil Soils 29:282-290

Beltrán, M. (2009). Evaluación del efecto del sistema de producción del cultivo del arroz (secano e inundado) sobre la población microbiana y la actividad enzimática asociada al metabolismo edáfico del fósforo. Tesis de Maestría. Facultad de Ciencias. Universidad Nacional de Colombia. Sede Bogotá.

Bernal, E., Celis, S., Galindez, X., Moratto, C., Sanchez, J. y García, D .(2006) Microflora cultivable y endomicorrizas obtenidas en hojarasca de bosque (páramo Guerrero -finca puente de tierra) Zipaquirá, Colombia. Acta biol.Colomb 11(2) 125-130.

Bowen, G. (1979). Integrated and experimental approaches to the study of growth of organisms around roots, p. 209-227. In B.j Schippers and W. Gams (ed.), Soil-borne plant pathogens. Academic Press, Inc., London.

Bray, R. y Kurtz, L. (1945), Determination of total, organic and available forms of phosphorus in soils Soil Sci. 59(1): 39-46.

Brito, E., Dusi, A., Xavier, G. y Rumjanek, N. (2008). Rizosphere bacterial communities of potato cultivars evaluated through PCR-DGGE profiles. Pesq.agropec.bras. Brasilia 43(5) 605-612.

Bouyoucos , G. (1962). Hydrometer method improved for making particle size analysis of soil. Agronomy Journal 54:464-465.

Calvo, P., Meneses, l. y Zuñiga, D. (2008). Estudio de las poblaciones microbianas de la rizósfera del cultivo de papa (Solanum tuberosum) en zonas altoandinas. Ecología aplicada 7(1,2) 141:148.

Corporación Autónoma de Boyacá (CORPOBOYACA), Corporación Autónoma de la Represa de Chivor (CORPOCHIVOR). (2005). Plan de acción Páramo Rabanal 2005-2010. Documento Técnico.

Crossley, D., Mueller, B. y Perdue, J. (1992). Biodiversity of microarthropods in agricultural soils: relations processes. Agric. Ecosyst. Environ 40: 37-46.

Feng, K., Lu, H., Sheng, H., Wang, X. y Mao, J. (2004). Effect of organic ligands on biological availability of inorganic phosphorus in soils. Pedosphere 14(1):85:92. 
Fernández. L., Zalba, P. y Gómez, M. (2005). Bacterias solubilizadoras de fosfato inorgánico aisladas de suelos de la región sojera. Ci. Suelo (Argentina) 23 (1):31-37.

Flórez, N. y Uribe, D.(2011). Biological and Physicochemical Parameters Related to the Nitrogen Cycle in the Rhizospheric Soil of Native Potato (Solanum phureja) Crops of Colombia. Applied and Environmental Soil Science. Vol 2011: 1:10.

Glick, B. (1995). The enhancement of plant growth by free living bacteria. Can.J. Microbiol. 41:109-117.

Grayer, R., Vieira, R., Price, A., Kite, G., Simon, J. y Paton, A. (2004).Characterization of cultivars within species of Ocimun by exúdate flavonoid profiles. Biochemical Systematics and Ecology 32: 901-913.

Grayston, S., Griffith, G., Mawdsley, J., Campbell, C. y Bardgett, R. (2001). Accounting for variability in soil microbial communities of temperate upland grassland ecosystems. Soil Biol Biochem 33:533-551.

Guang-Can, T., Shu-tun, T., Miao-Ying, C. y Guang-hui, X. (2008). Phosphate solubilizing and mineralizing abilities of bacteria isolated from soils. Pedosphere 18(4):515-523.

Gyaneshwar, P., Naresh, G., Kumar, L., Parekh, J.. y Poole, P. (2002). Role of soil microorganisms in improving P nutrition of plants. Plant and Soil 245: 83-93.

Horwitz, W. (2000).Official Methods of Analysis of AOAC International, AOAC International, Gaithersburg, 2000

Katznelson, H., Peterson, E. y Roualt, J (1962). Phosphate-dissolving microorganisms on seed and in the root zone of plants. Can. J. Bot. 40: 1181-1186.

Killian, M., Steiner, U., Krebs, B., Junge, H., Schmiedeknecht, G. y Hain, R. (2001). FZB24® Bacillus subtilis mode of action of a microbial agent enhancing plant vitality. Pflanzenschut - Nachrichten Bayer 53(1): 72-93.

Kim, Y., Kim, I., Moon, E., Park, J., Kim, S., Lim, J., Park, B. y Lee, E. (2011). High abundance and role of antifungal bacteria in compost-treated soils in a wildfire area. Microb Ecol 62:725-737.

Kobus, J. (1962). The role of microorganisms in the transformation of phosphoric compounds in the soil. Acta Microbiol. Pol.11:255-262

Kucey, R., Janzen, H. y Leggett, M. (1989). Microbially mediated increases in plant-available phosphorus. Adv. Agron.42:199-228.

Lizarazo, M. (2005). Grupos funcionales de microorganismos del suelo: ciclos del carbono, nitrógeno, fósforo y azufre. Suelos Ecuatoriales 35 (1):59-65 
Loper, J., Haack, C. y Schroth, M. (1985). Population Dynamics of Soil Pseudomonads in the rhizosphere of potato (Solanum tuberosum L.) Applied and Environmental Microbiology, 49(2): 416-422.

Ministerio de ambiente, vivienda y desarrollo territorial - FEDEPAPA. (2004). Guía ambiental para el cultivo de la papa. Dirección de desarrollo sectorial sostenible. ISBN 958-97393-5-0.

Moratto, C., Martínez, L., Valencia, H. y Sánchez, J. (2005). Efecto del uso del suelo sobre hongos solubilizadores de fosfato y bacterias diazotróficas en el páramo de Guerrero (Cundinamarca). Agronomía Colombiana 23(2): 299-309.

Naik, P., Raman, G., Narayanan, K. y Natarajan, N. (2008). Assesment of genetic and functional diversity of phosphate solubilizing fluorescent pseudomonads isolated from rhizospheric soil. $B C M$ Microbiology (8)230:1-14.

Nautiyal, C. (1999). An efficient microbiological growth medium for screening phosphate-solubilizing microorganisms. FEMS Microbiology Letters 170: 265-270.

Nieto, P. y García, D. (2010). Bacterias diazotroficas y solubilizadoras de fósforo aisladas de las especies forestales altoandinas colombianas Weinmannia tomentosa y Escallonia myrtilloides. Rev. Intropica. 5: $63-76$.

Osorio, N. (2010) Microorganismos del suelo y su efecto sobre la disponibilidad de nutrientes en suelos ácidos del trópico. Suelos Ecuatoriales 41 (1):74-91.

Rangel, O. (2000). Colombia Diversidad Biótica III La región de vida paramuna. Universidad Nacional de Colombia- Instituto de Ciencias Naturales, Instituto de Investigación en Recursos Biológicos Alexander von Humboldt.

Rodríguez, H. y Fraga, R. (1999). Phosphate solubilizing bacteria and their role in plant growth promotion. Research review paper. Biotechnology Advances 17: 319-339.

Rubio, G. (2002). Conectando el fósforo del suelo con la planta. Informaciones agronómicas del cono sur. 16: 19:23.

Sarmiento, L., y Bottner, P. (2002). Carbon and nitrogen dynamics in two soils with different fallow times in the high tropical Andes: indications for fertility restoration Applied Soil Ecology 19: 79-89

Scholer, M., Dilly, O. y Munch, J. (2003). Indicators for evaluating soil quality. Agriculture, Ecosystems and Environment 98: 255-262.

Silva, K., Salles, F., Seldini, L. y Elsas, J. (2003). Application of a novel Paenibacillus-specific PCR-DGGE method and sequence analysis to asses the diversity of Paenibacillus spp. in the maize rhizosphere. Journal of Microbiological Methods. 54: 213-231. 
Sivila de Cary, R. y Angulo, W. (2006) Efecto del descanso agrícola sobre la microbiota del suelo (Patarani - Altiplano Central boliviano). Ecología en Bolivia 41(3): 103-115.

Sylvia, M., Fuhrmann, J., Hartel, P. y Zuberer, D. (1995). Principles and applications on soil microbiology. Second Edition. Prentice Hall. New Jersey.

Taylor, J., Wilson, B., Mills, M. y Burns, R. (2002). Comparison of microbial numbers and enzymatic activities in surface soil and subsoils using various techniques. Soil Biology y Biochemistry 34: 387401.

Torres, M. y Lizarazo, L. (2006) Evaluación de grupos funcionales (C, N, P) y actividad de la fosfatasa acida en dos suelos agrícolas del departamento de Boyacá (Colombia). Agronomía Colombiana 24(2): 317- 325.

Vanegas, J., Landazabal, J., Melgarejo, L., Beltrán, M., Uribe, D, (2013). Structural and functional characterization of the microbial communities associated with the upland and irrigated rice rhizospheres in a neotropical Colombian savannah. European Journal of Soil Biology 55:1-8

Vélez, N. (2009) Documento técnico de soporte para la declaratorio del parque natural regional Rabanal. Instituto Alexander Von Humboldt. Recuperado de http://www.condesan.org/ppa/sites/default/files/recursos/archivos/Documento\%20soporte\%20declaratoria\%20Rabanal.pdf

Walkley, A. y Black, I. (1934). An examination of Degtjareff method for determining soil organic matter and a proposed modification of the chromic acid titration method. Soil. Sci 37:29-38.

Wieland, R., Newmann, R. y Backhaus, H. (2001). Variation of microbial communities in soil, rhizosphere, and rhizoplane in response to crop species, soil type, and crop development. Applied and environmental microbiology 67(12): 5849-5854. 


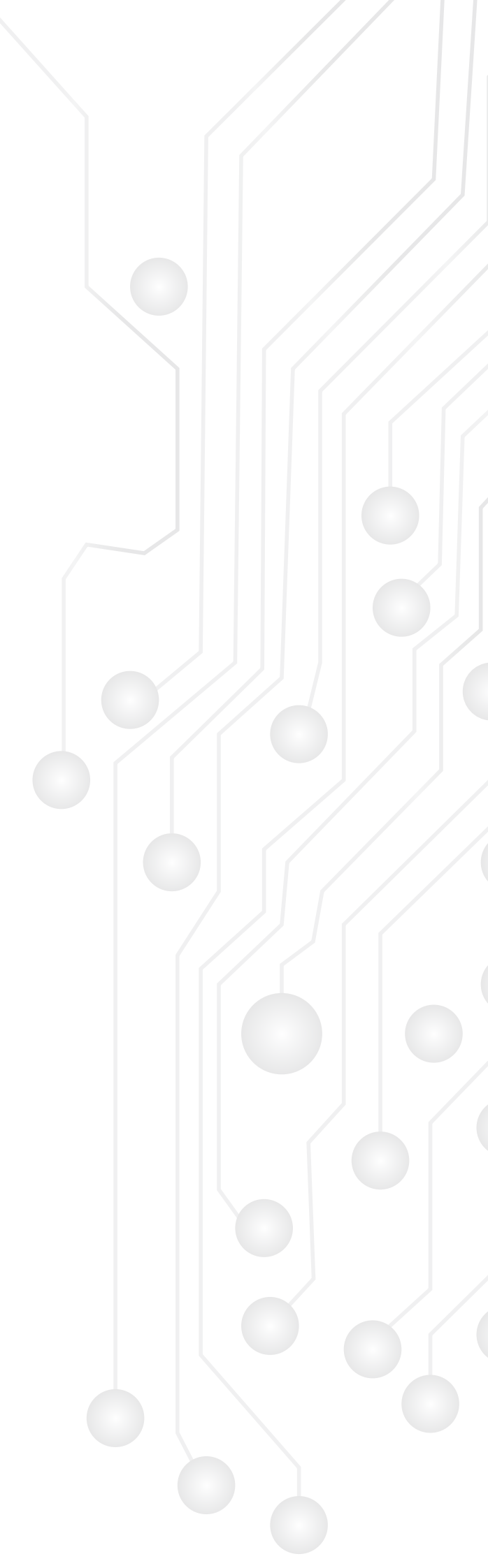

